On Skipjack Tuna Dynamics: Similarity at Several Scales

\author{
Aldo P. Solari, Jose Juan Castro, and Carlos Bas
}

\title{
CONTENTS
}

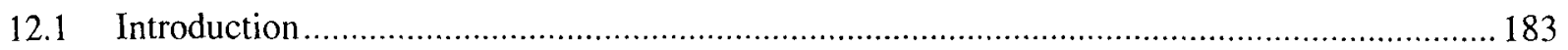

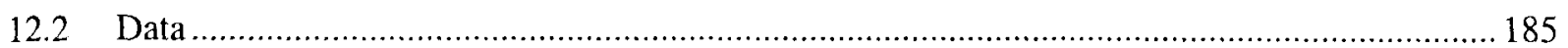

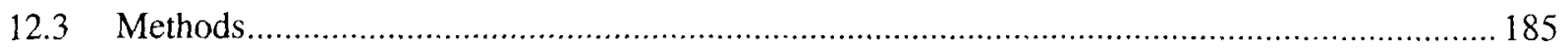

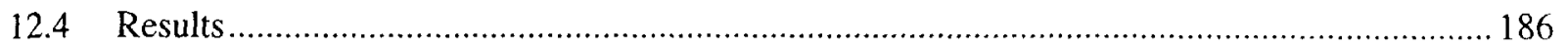

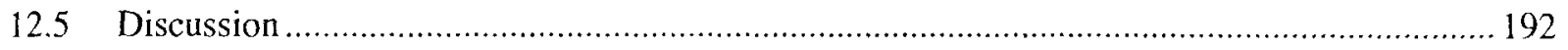

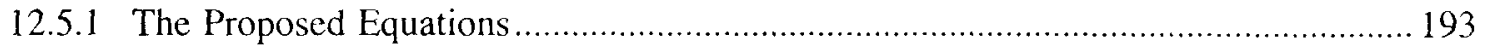

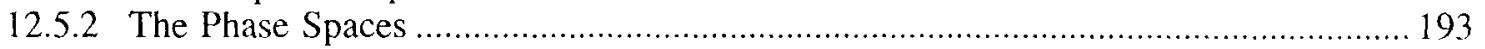

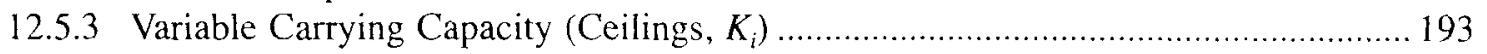

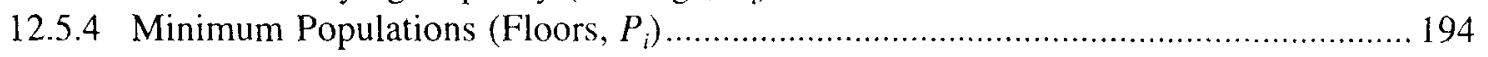

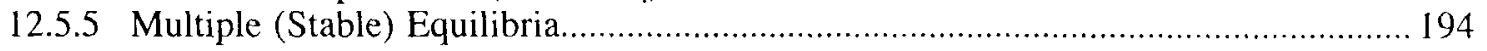

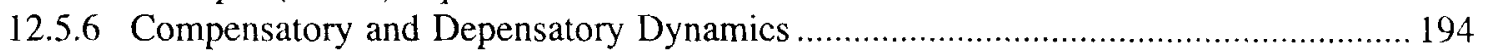

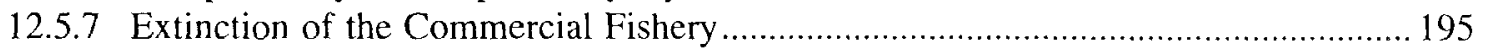

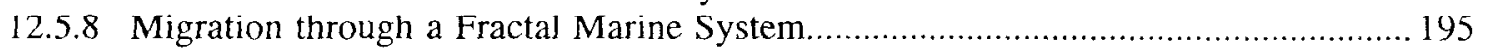

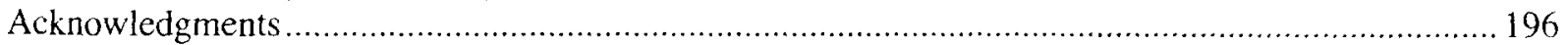

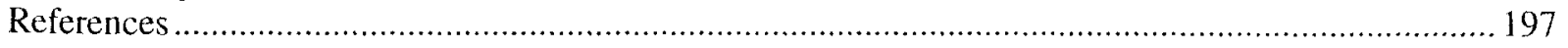

\subsection{Introduction}

The tuna resources in the Eastern Central Atlantic have been the object of both intensive fishery for over 30 years and numerous studies conducted under the coordination of the International Commission for the Conservation of Atlantic Tunas (ICCAT) (Fonteneau and Marcille, 1993). The skipjack tuna (Katsuwonus pelamis, henceforth referred as "skipjack") supports an important conmercial fishery across the Eastern Atlantic from the Gulf of Guinea to the southwestern Irish coast (ICCAT, 1986). Tag recovery studics have indicated that skipjack migration routes lie from the southeast toward the north and northwest Atlantic (Ovchinnikov et al., 1988) and catches on the highly migratory tuna stocks are due to multigear fisheries (Fontencau, 1991). Also, both the spatiotemporal distribution and abundance of skipjack tuna have been related to causes such as environmental requirements and feeding (Ramos et al., 1991), upper ocean dynamics (Ramos and Sangrá, 1992), hydro climatic factors (Pagavino and Gaertner, 1994), prey abundance (Roger, 1994a, b, Roger and Marchal, 1994), themal habitat (Boehlent and Mundy, 1994), schooling behavior (Bayliff, 1988; Hilborn, 1991), mesoscale frontal ocean and upwelling dynamics (Fiedler and Bernard, 1987; Ramos et al., 1991), as well as several other aspects beyond the scope of the present chapter. Skipjack tuna appears to be able to adapt the reeding strategy to environmental conditions preying upon what it encounters (Roger, 1994a, b) and the $18^{\circ} \mathrm{C}$ isotherm and $3 \mathrm{~m}$ oxygen per liter isoline are considered lower limiting factors (Piton and Roy, 1983). The exploitation rate on 
most tuna stocks has been constantly increasing and assessments have been inefficient in estimating the real maximum sustainable yield of those stocks (Fonteneau. 1997). In the Atlantic, luna catches were suggested to be both underestimated and misreported (Wise, 1985) and, despite the high level of fishing effort, recruitment overfishing has never heen suggested for skipjack (Fonteneau. 1987).

Skipjack data are, generally, studied in light of the early population models (henceforth referred as "classical approaches/models") by Beverton and Holt (1957) and Ricker (1954). These models are still being used to provide quantitative advice to fishery managers (Gulland, 1989) and proposed extinction curves where recruitment either reaches an asymptotic maximum (Beverton-Holt) or becomes low at high spawning stock sizes (Ricker). These classical approaches became widely accepted functions to describe the stock-recruitment relationship and they introduced a general, nonlinear framework into fish population dynamics. However, they had a limited capacity both to include key factors of specific situations and to link internal (population) and external (environmental) dynamics to each other. This lack of specificity has been discussed in the literature by Clark (1976), De Angelis (1988), Fogarty (1993), and other authors. Also, classical models assumed that populations under exploitation were naturally limited in a way that will permit them to respond in a compensatory way to fishing (Beverton and Holt, 1957; Ricker, 1975; Cushing, 1977; Rothschild, 1986). The classical models excluded dynamic features critical to understand the mechanics behind the data (linking and transition mechanisms between steady states, system behavior, extinction of the commercial fishery, environmental interactions, among other factors). However, two more advanced frameworks were proposed during the 1970s and 1980s. On the one hand, Paulik (1973) described an overall spawner-recruit model, which was formed from the concatenation of survivorship functions. This approach could exhibit multiple (stable) equilibria and complex dynamics and was the result of a multiplicative process where the initial egg production could be modified by nonlinear functions specific to each life stage and cohort population size: the main shortcoming was the interdependency between the functions due to the multiplicative nature of the model. On the other hand, Shepherd (1982) unified the dome-shaped and asymptotic approaches proposed by Ricker (1954) and Beverton and Holt (1957), respectively, but could incorporate neither multiple stable equilibria nor depensatory dynamics. In our view. there was an urgent need to develop a flexible framework that would allow us both to ask better questions and to understand causal mechanisms to dynamic patterns behind the data.

In previous papers by Solari et al. (1997), Bas et al. (1999), and Castro et al. (1999). we proposed recruitment both to the population (influx of juveniles to the adult population), area (micration of cohorts/individuals into fishery areas), and fishery (dynamics of the fishery) as a system or summation of nonlinear functions (multiple steady states) with dynamic features ranging from chatos (when external conditions are extremely benign), through a range of relatively stable, converging cycles (as external stress increases), to a quasi-standstill state with no clear oscillations (when the minimum viable population is being approached). The system was suggested to have the capacity to evolve persistently and return within a wide range of equilibrium states allowing for multiple carrying coproition as well at density dependent (compensation and depensattion due population numbers) density-independent compensation and depensil ion due environmental fluctuations and fisheries) and inverse-density-dependent (per capita reproductive sucess and recruitment decline's at low population levels) coupled mechanics. Our new, dymanic frameswork was justifiable on an ad here basis because of the hexibility it afforded. Also, it offered some conceptual advantages over classical approaches as it allowed for (1) multiple equilibria, which could be independent from each other and operate at the same time (no mathematical interdependence between the functions due to the additive nature of the approach); (2) either higher or lower equilibria could be incorporated into the system: (3) transitions between equilibria due to density-dependent and density-independent oscillations could be linked; and, among other features, (4) several maxima and minima and depensatory dynamics could be described in the same relationship allowing for simultaneous equilibrium states at different spatiotemporal scales and substocks. This model allowed us both te approach the dynamics of the skipjack from a me" perspective and investigate whether there was any dymanie similarity, at several spatial scales, in the captures of this migratory stock. The aims of the present study were to (1) analye three independent skipjack fishery landing series representing catches from three different spatial scales: (2) determine whether there may he any similarity between the series; and (3) discuss new concepts to study the erolution of both recruitment. to-the-area and the dynamics and future approatehes to skipjack populations in the Eastern Central Atlantic. 


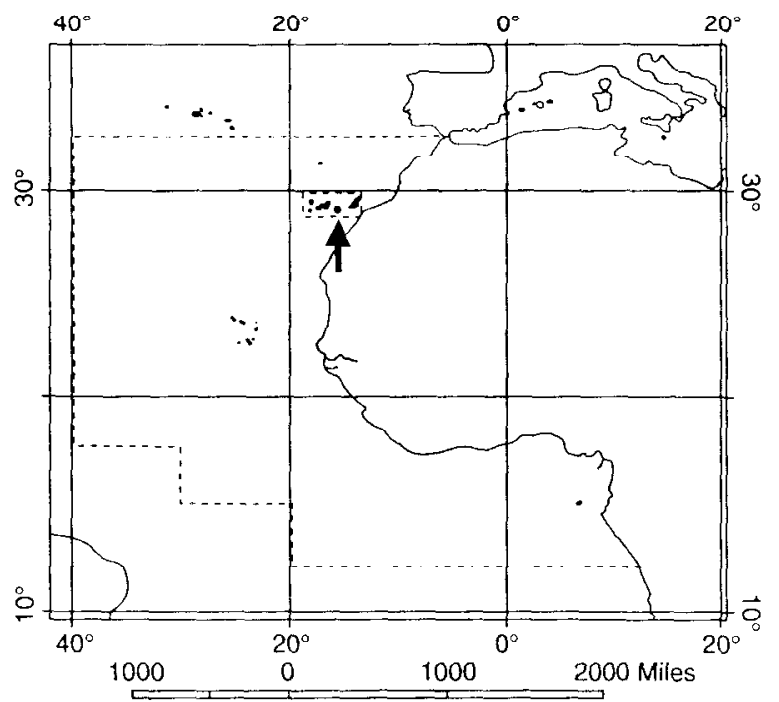

FIGURE 12.1 Three spatial scales of skipjack tuna sampling. The CECAF (Committee for Eastern Central Atlantic Fisheries) Division 34 (larger area indicated by the dashed line; from Gibraltar to the Congo River, Lat. $36^{\circ} 00^{\prime} \mathrm{N}-6^{\circ} 04^{\prime} 36^{\prime \prime} \mathrm{S}$, Long. $12^{\circ} 19^{\prime} 48^{\prime \prime} \mathrm{E} 5^{\circ} 36^{\prime} \mathrm{W}$ ); the Canary Islands archipelago (minor area indicated by the dashed line, Lat. $29^{\circ} 40^{\prime} \mathrm{N}-27^{\circ} 10^{\prime} \mathrm{N}$, Long. $13^{\circ} \mathrm{W}-18^{\circ} 20^{\prime} \mathrm{W}$ ), and the Port of Mogan (local waters off the southern shore, island of Gran Canaria, Lat. $27^{\circ} 55^{\prime} \mathrm{N}$-Long. $15^{\circ} 47^{\prime} \mathrm{W}$, indicated by the arrow). (Map modified from FAO, 2001.)

\subsection{Data}

The skipjack fishery series analyzed herein (annual catches in metric tonnes, Tn) were the following:

1. Landings due to a local bait fishery at the Port of Mogan (Lat. $27^{\circ} 55^{\prime} \mathrm{N}$, Long. $15^{\circ} 47^{\prime} \mathrm{W}$, henceforth referred as the "Mogan series"), island of Gran Canaria (Canary Islands, Spain), years 1980-1996 according to Hernández-García et al. (1998)

2. Overall pooled landings due to local bait fisheries for the whole of the Canary Islands area (Eastern Central Atlantic, Lat. $29^{\circ} 40^{\prime} \mathrm{N}-27^{\circ} 10^{\prime} \mathrm{N}$, Long. $13^{\circ} \mathrm{W}-18^{\circ} 20^{\prime} \mathrm{W}$, henceforth referred as "Canarian series"), years 1975-1993 according to Ariz et al. (1995)

3. Pooled landings due to multigear (bait, long-line, and purse-seine) both oceanic and coastal fisheries within the CECAF (Committee for Eastern Central Atlantic Fisheries) Division 34 (from Gibraltar to the Congo River, Lat. $36^{\circ} 00^{\prime} \mathrm{N}-6^{\circ} 04^{\prime} 36^{\prime \prime} \mathrm{S}$, Long. $12^{\circ} 19^{\prime} 48^{\prime \prime} \mathrm{E}-5^{\circ} 36^{\prime} \mathrm{W}$; henceforth referred as the "CECAF series"), years 1972-1996 according to HISHSIAI/FAO (1999).

Figure 12.1 shows these spatial scales (map modified after FAO, 2001): a point (waters off the Pon of Mogan), a minor area (waters within the (anary Islands archipelago), and a relatively large ocean area (the CECAF area 34). Figure 12.2 shows the skipjack series from each location.

\subsection{Methods}

We standardized the series to the same scale $(Z$ values with mean $=0$ ) to facilitate both the analyses and visual comparison. We used both $t$-tests and autocorrelations to determine the homogeneity between the series and indications of autosimilarity. Also, the Welch method (after Oppenheim and Schafer, 1975) was used to estimate the spectral density. The phase spaces (stock-in-area against recruits-to-the-area) were obtained by plotting data values from a certain year $\left(N_{t}\right)$ against values the year after $\left(N_{t+1}\right)$. Crosscorrelations were used to determine the degree of correspondence between the series. Furthermore, data values were fitted both by linear regressions through the origin (to determine the "replacement line" or recruitment needed to replace the stock-at-spatial-location) and sixth-order polynomials (to describe the 

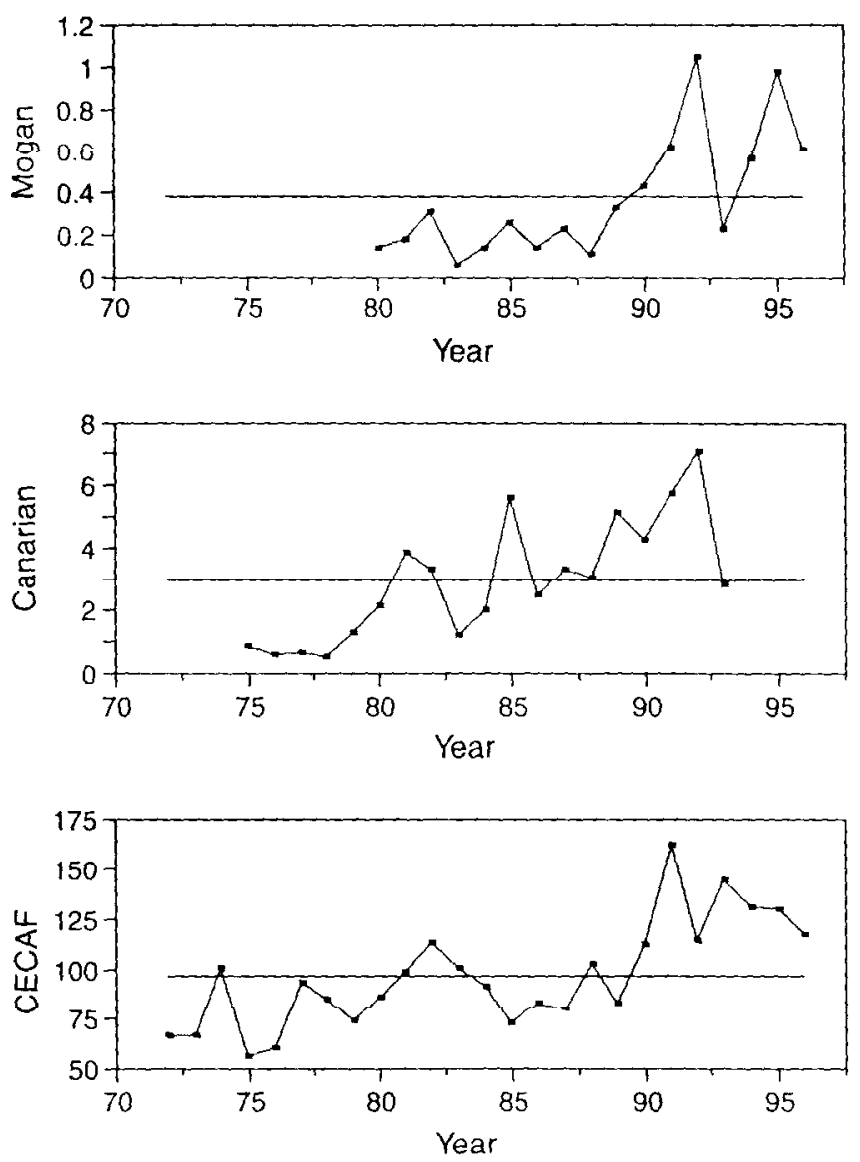

FIGURE 12.2 Skipjack tuna series $\left(\mathrm{Tn}^{*} 10^{3}\right.$ ) from a local bait fishery at the Port of Mogan (island of Gran Canaria, Canary Islands, years 1980-1996), after Hernández-García et al. (1998); overall pooled landings due to local bait fisheries for the whole of the Canary Islands area (years 1975-1993), after Ariz et al. (1995); and pooled landings due to multigear (bait, long-line, and purse-seine) both oceanic and coastal fisheries within the CECAF Division 34 (years 1972-1996), after FISHSTAT/FAO (1999). The catches represent sampling series from three significantly different spatial scales. The straight lines indicate the mean of the series.

dynamic features of the systems). To set the final, schematic example, we simulated sinusoidal waves with an arbitrary noise to represent the proposed system.

\subsection{Results}

We start this section with a general figure showing the difference between the classical approaches based on a unique equilibrium and our new. nonlinear framework. This preliminary step is helpful for understanding the rest of the chapter and it shows some of the guidelines to apply our multiple steady state model to the plane $N_{t}$ against $N_{t+1}$ attempting to understand the dynamic features we propose.

On the one hand, the Shepherd (1982) functional form is given by

$$
R=\frac{\alpha \cdot S}{1+\left(\frac{S}{K}\right)^{\delta}}
$$

where $R$ is recruitment, $S$ is the spawning stock abundance, and $K$ the threshold abundance above which density-dependent effects dominate (i.e., the carrying capacity). The parameters $\alpha$ and $\delta$ are referred to as the slope at the origin and degree of compensation involved, respectively. This approach could unify. within a single framework, both the classical dome-shaped (for $\delta>1$ ) and asymptotic (for $\delta=1$ ) functional forms proposed by Ricker (1954) and Beverton and Holt (1957), respectively. An example for each of the models is shown in Figure 12.3. 


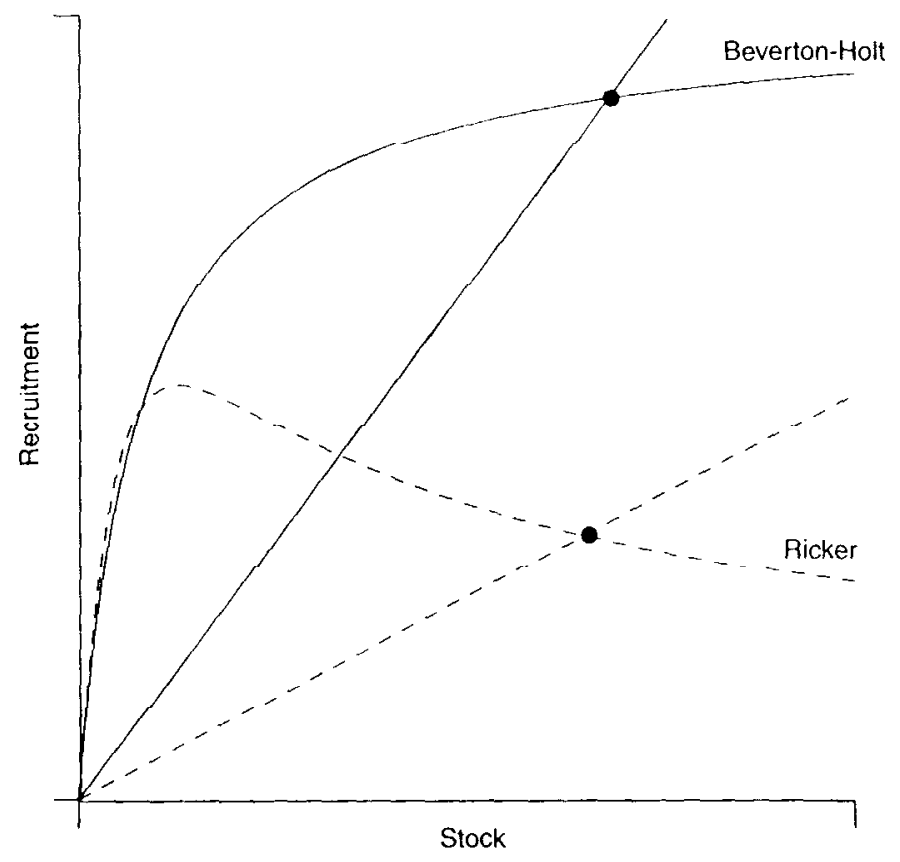

FIGURE 12.3 Two examples of the Shepherd (1982) function, which unified, within a single framework, the classical dome-shaped and asymptotic functions proposed by Ricker (1954, dashed curve) and Beverton-Holt (1957, continuous curve). The stock-recruitment relationship is assumed to (1) be govemed by a single stable equilibrium (dot) shown by the intersection of the function with a simple regression through the origin (i.e., the replacement line); (2) respond solely in a compensatory way to fishing, and (3) become either asymptotic (Beverton-Holt) or be limited by a single carrying capacity (i.e., threshold abundance above which density-dependent effects dominate; Ricker).

On the other hand, recruitment $(R)$ in our framework is defined (Equation 12.2) as the summation of nonlinear functions of spawning stock, $S$, given by

$$
R \cong \sum_{i=1}^{m} \frac{a_{i} \cdot(S)}{\left(S-b_{i}\right)^{2}+c_{i}}
$$

where the entries $i=1 \ldots m$ represent the number of equilibrium states in the stock-recruitment (SR) system, with $m$ the highest equilibrium where the SR relationship reaches the ceiling or maximum allowable carrying capacity. Equilibrium states are controlled by the coefficients $a_{i}$ (slope of the curve at the origin), with $b_{i}$ and $c_{i}$ the density-dependent mortality entries. For example, $a_{i}$ fulfills a similar function to the natural rate of increase in the logistic equation. These coefficients define each equilibrium state and their values may be fixed. Also, values of $b_{i}$ define lie ranges of spawning stock for which equilibrium states may arise. A graphical representation of a dynamic system with $m$ equilibrium states is shown in Figure 12.4. This new approach can be applied to the plane $N_{t}, N_{t+1}$ to describe dynamics in both migration and catches (recruitment to the area) in skipjack and link local and mesosealar trends from different spatial scales, as well. An $m$ number of oscillatory phenomena ranging from limit cycles to chaos and inverse density dependence are allowed in this system, which may be approximated either by least squares using Equation 12.2 or by polynomial regressions incorporating three constants for each equilibrium state. The objective of the sixth-order fittings we use is to describe in a familiar way to all readers the multiple steady-state cases we approach. Further aspects of this new model are well detailed in Solari et al. (1997).

We have assumed a positive relationship between the number of juveniles being recruited to the population and those entering the area of the fishery; this implies that the number of recruits-to-the-area in a migratory stock may increase as recruitment increases in the remote nursery areas. Also, we have regarded the analyzed series as statistically independent as a result of the different sources and relatively large geographic range of the areas concerned; paired $t$-tests $(p<0.001 \mathrm{in}$ all of the cases) showed the series may represent three significantly different levels of recruitment. Furthermore. in spite of the limited degrees of freedom in all of the series, the autocorrelation values were $0.42(p=0.06), 0.52(p=0.01$. 


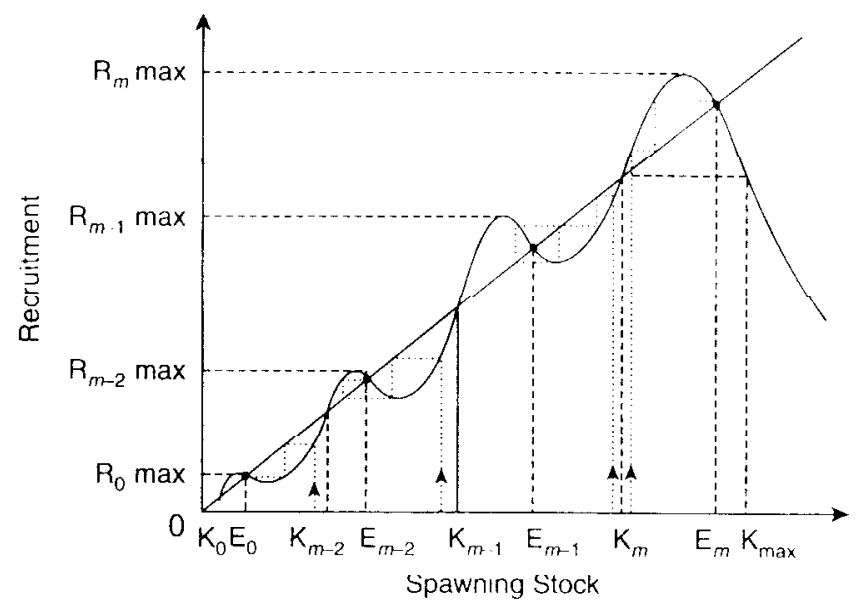

FIGURE 12.4 Graphical representation of a dynamic system with $m$ equilibrium states (Equation 12.2) proposed by Solari et al. (1997). This new approach can be applied to the plane $N$, vs. $N_{t}$ to describe dynamics in hoth migration and catehes (recruitment to the area) in skipjack tuna ( $K$. pelamis) at three spatial scales (CECAF Area 34. Canary Islands area, and Port of Mogan, Central East Atlantic). $K_{m}, K_{m-1}, K_{m-2}$ represent both the minimum viable populations for the equilibrium states $m, m^{-1}$, and $m^{-2}$ and the carrying capacities for their immediate lower equilibria, respectively. $E_{m}, E_{m-1}, E_{m-2}, E_{0}$ represent equilibria around which the SR relationship may turn in density-dependent compensation and depensation phases. $K_{\text {max }}$ is the maximum allowable carrying capacity and any values of stock surpassing this ceiling will induce a shift toward lower equilibria. $K_{0}$ is the floor or minimum viable population below which the SR relationship may tend to zero (extinction of commercial fishery). System persistence and local stability are shown in all three cases of stability analyses (dotted lines) while $K_{0}<S<K_{\max }$ and $R\left(K_{0}\right)<R<R_{\max }$. An $m$ number of oscillatory phenomena ranging from limit cycles to chaos and inverse density-dependence are allowed in this system. Each equilibrium state may represent stock and recruitment to the area in a certain spatial location and link local and mesocalar dynamics.

lag $=1)$ and $0.56(p=0.003$, lag $=1)$ for the Mogan, Canarian, and CECAF series, respectively. These results may suggest that there is a certain autosimilarity or "memory" in the series implying that the skipjack slock a cerlain year may depend on the abundance in preceding years. Moreover, the spectral density of the series detected maxima around the periods of 3 to 4 years in all of three series (Figure 12.5). Only 14 years were common to all series and, consequently, the spectral analyses should be interpreted independently for each tinle series. Likewise, the cross-correlations showed a certain degree of correspondence between the series; we tested for several time lags and the highest obtained values were 0.84 (Mogan-Canarias series, lag = 0), 0.56 (Canarian-CECAF series, lag =1), and 0.68 (Mogan-CECAF scries, lag -1). The lag 1 between the CECAF and Canatian and Mogan series may be a consequence of the reduction of the spatial scale.

Figure 12.6 through Figure 12.8 show the phase spaces for the Mogan, Canarian, and CECAF series, respectively. The linear regression through the origin represents both the recruiment needed a replace the stock-at-spatal-location and overall equilibrium values. Furthermore. the polynomal regressons describe the dynamic features. which may be common io all of the three cises: (1) a relatively high equilibrium state (indicated by " $\mathrm{A}$ ") with high kevels of both captures and recruitmenth where maxima and minima diverge and (2) a relatively low equilibrium state (indicated by "B") with lower levels of both captures and recruitment where maxima and minima converge. A summary of results from the linear and polynomial regressions is shown on Table 12.1. Also, there may be an indication of a third equilibrium state both in the cases shown in Figure 12.7 (for years 1975 through 1978) and Figure 12.8 (between $\mathrm{A}$ and $\mathrm{B}$ ). Figure 12.6 through Figure 12.8 show the principal results in this chapter. The plane $N_{r} . N_{t+1}$ fitted by a third degree polynomial and a simple regression may allow us to casily understand the dynamics behind the data and both describe and link them through our multiple steadystate approach. Other nonlinear models may be used both to fit the data and to ohtain several equilibrium states. However, our approach can be used as an ad here model because it allows great flexibility and may link and explain most population dynamic phenomena (compensation, depensation. density dependence, density independence. inverse density depensation. and dynamic system hehavior in a relatively simple framework taking into consideration different spatial seales and substocks. No references describing such a dynamic similarity at several spatial scales were found in the literature 

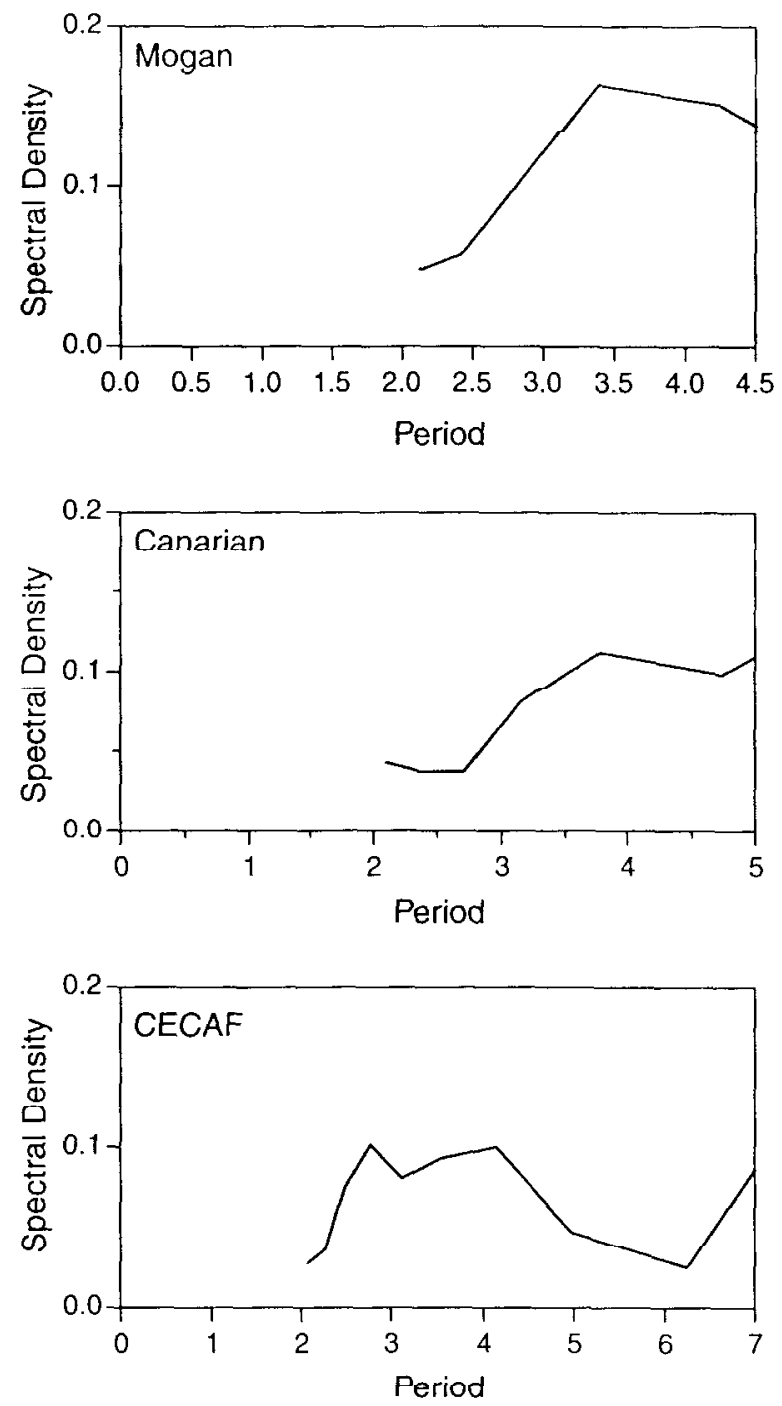

FIGURE 12.5 The spectral densities of three skipjack tuna series from the Port of Mogan (island of Gran Canaria, Canary Islands, years 1980-1996, Mogan series, after Hernández-García et al., 1998), the whole Canary Islands area (years 1975-1993, Canarian series, after Ariz et al., 1995), and the CECAF Division 34 (years 1972-1996, CECAF series, after FISHSTAT/FAO, 1999).

on skipjack tuna and we were able to detect this dynamic autosimilarity while interpreting lle dala in light of our model.

To illustrate the dynamic features we have proposed, we show, in Figure 12.9, a schematic example on arbitrary data (sinusoidal waves plus noisc) of a theorctical in-area stock and recruitment system where the following features are described:

1. The linear regression represents an overall replacement line: while the system evolves above the linear fit, compensation operates and numbers grow, whereas depensation operates under the replacement line implying that numbers decrease.

2. A high and a luw equilibrium state represented by A and B, respectively. These orbits of stability (indicated by the dashed ellipses) are caused by oscillations due to density-dependent compensatory and depensatory phases (indicated by the arrows on the ellipses). Also, the polynomial regression describes the two-steady-state system, the evolution of equilibria and the shift between equilibria as both the floor of equilibrium $A$ and the carrying capacity of equilibrium $B$ are approached (indicated by the dot).

3. Also, density-independent transitions may occur due to changes in the environment and fishing mortality: as the lower equilibrium state approaches the ceiling or particular carrying capacity 


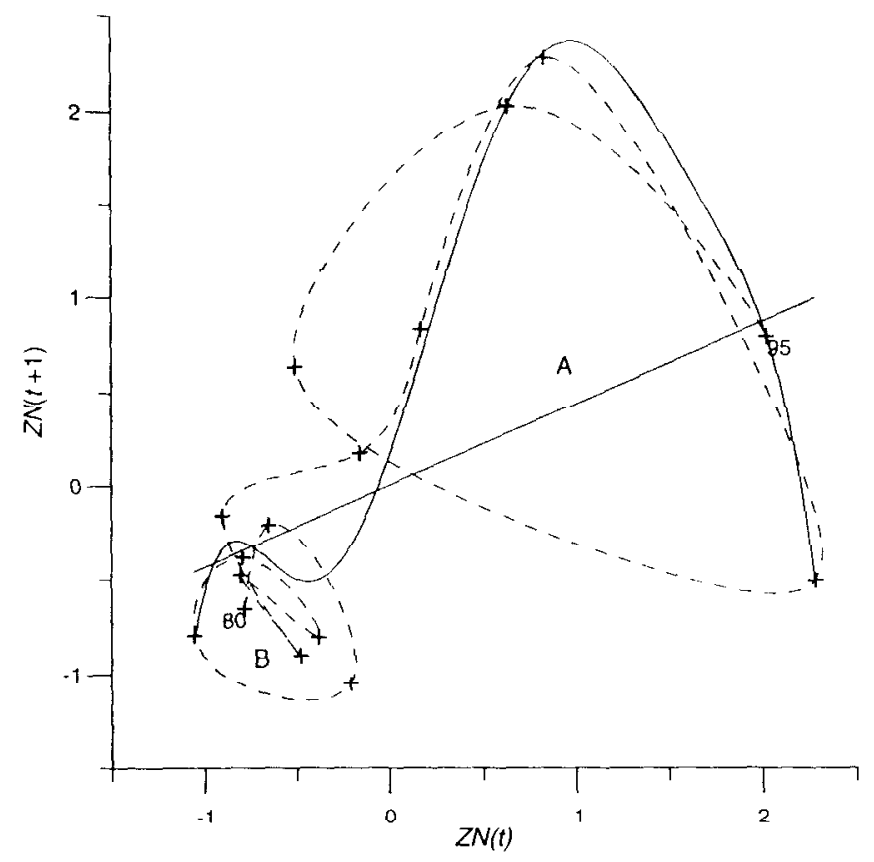

FIGURE 12.6 Phase space for the skipjack fishery landing series at the Port of Mogan (island of Gran Canaria, Canary Islands). The linear regression through the origin represents both the recruitment needed to replace the stock-at-spatial. location and overall equilibrium values. The sixth-degree polynomial regression describes the evolution of the high and low steady-states indicated by "A" and "B," respectively. $Z$ indicates standardized values and $N_{t}$ and $N_{t+1}$ the generation of the values; 80 and 95 indicate the start and end year of the plotted values.

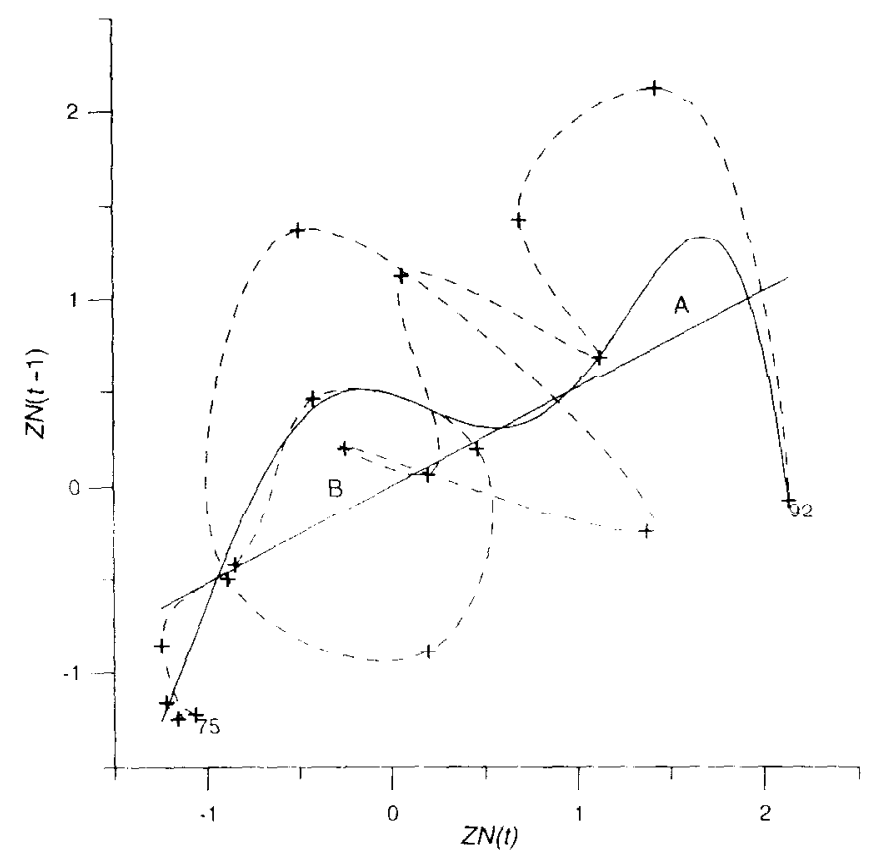

FIGURE 12.7 Phase space for the skipjack fishery landing series from the Canary Islands area (Eastern Central Atlantic). The linear regression through the origin represents both the recruitment needed to replace the stock-at-spatial-location and overall equilibrium values. The sixth-degree polynomial regression describes the evolution of the high and low steady states indicated by "A" and " $\mathrm{B}$," respectively. $Z$. indicates standardized values and $N_{f}$ and $N_{t+1}$ the generation of the values; 75 and 92 indicate the start and end year of the ploued values.

(indicated by the dot), the system may shift toward a higher equilibrium through a densityindependent compensatory phase. Moreover, while density-dependent depensation operates in the higher equilibrium state and the floor of $\mathrm{A}$ is approached, density independent depensation may shift the system toward the lower equilibrium state. 


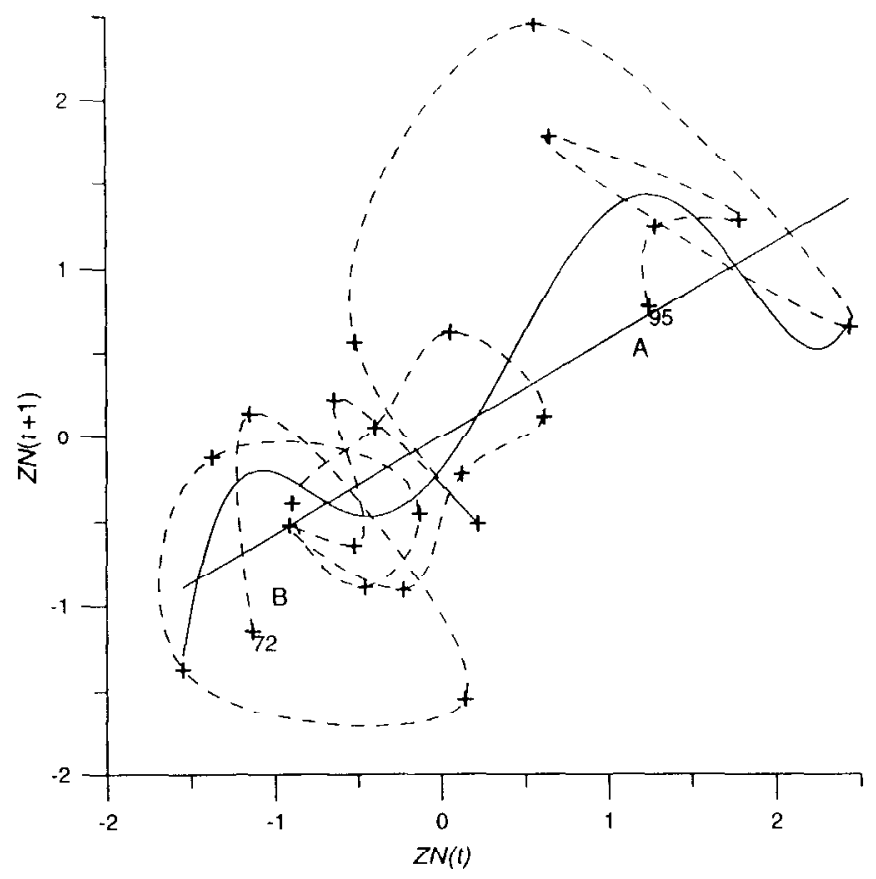

FIGURE 12.8 Phase space for the skipjack fishery landing series from the CECAF Division 34 (Eastern Central Atlantic). The lincar regression through the origin represents both the recruitment needed to replace the stock at-spatial-location and overall equilibrium values. The sixth-degree polynomial regression describes the evolution of the high and low steady states indicated by "A" and "B," respectively. $Z$ indicates standardized values and $N_{t}$ and $N_{t+1}$ the generation of the values; 72 and 95 indicate the start and end year of the plotted values.

\section{TABLE 12.1}

Summary of Results from Data Fits upon the Steady-State Systems Proposed for the Skipjack Tuna Series (standardized values) from Three Spatial Scales (Port of Mogan, Canary Islands area, and CECAF Division 34)

\begin{tabular}{|c|c|c|c|c|c|c|}
\hline \multirow[b]{2}{*}{ DF } & \multicolumn{3}{|c|}{ Linear Trend } & \multicolumn{3}{|c|}{ Polynomial (6th order) } \\
\hline & $\boldsymbol{R}$ & $F$ & $p<$ & $\boldsymbol{R}$ & $F$ & $p<$ \\
\hline 15 & 0.44 & 3.35 & 0.09 & 0.92 & 7.77 & 0.01 \\
\hline 17 & 0.54 & 6.5 .5 & 0.05 & 0.77 & 2.63 & 0.08 \\
\hline 23 & 0.59 & 11.62 & 0.01 & 0.70 & 2.66 & 0.06 \\
\hline
\end{tabular}

4. Maxima and minima converge as the system evolves toward the lower equilibrium and diverge as it shifts toward the higher steady state. Density dependence may operate similarly in both equilibrium states but at different levels of numbers. On the one hand, oscillations may be larger in high equilibrium states as the system evolves toward the maximum carrying capacity of the system (a critical value or overall ceiling above which the trajectory enters depensation, $K_{\max }$ ); on the other hand, oscillations may become lower as the system evolves toward a minimum viable population (a critical value around which oscillations become small or nonexistent implying the extinction of the commercial fishery).

The proposed two-steady-state system may be described either by a multiplicative equation such as

$$
R_{a} \cong f_{1}\left(S_{A}\right) \cdot f_{2}\left(S_{B}\right)
$$




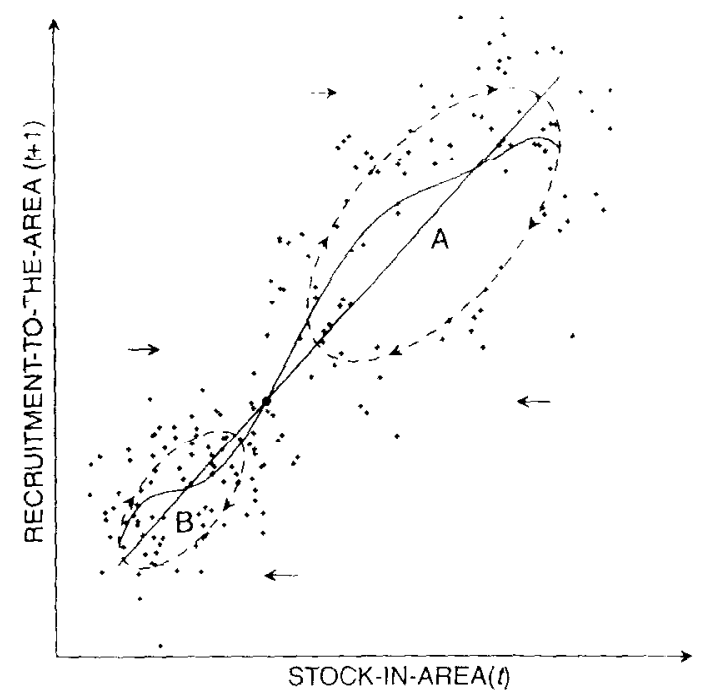

FIGURE 12.9 Theoretical in-area stock and recruitment system proposed for three spatial scales in the Eastern Central Atlantic (Port of Mogan, Canary Islands area and CECAF Division 34). The linear regression represents the replacement line and the polynomial fit describes the dynamic evolution of the system. A and B are the high and low equilibrium states, respectively. The dot represents the transition point between the steady states, being the floor of $A$ and canying capacity of B, respectively. Density-independent compensation and depensation are represented by the arrows $\rightarrow$ and $\leftarrow$, respectively. Orbits of stability are indicated by the dashed ellipses on which arrows represent density-dependent compensation and depensation. Data values are arbitrary and were generated by sinusoidal waves plus noise.

or an additive model such as

$$
K_{a} \cong f_{1}\left(S_{A}\right)+f_{2}\left(S_{B}\right)
$$

where $R_{a}$ represents recruitment, $f_{1.2}$ are nonlinear, three parameter functions, and $S_{A . B}$ are the stock-inarea for the equilibrium states $\mathrm{A}$ and $\mathrm{B}$, respectively.

\subsection{Discussion}

Although skipjack harvesting is subject to some form of international regulation. control is minimal and we have regarded it as an open-access fishery: exploitation may be carried out in international waters on the migratory stock without any effective policy enforcement. In the present approach, recruitmentto-the-area is a key concept, which describes a migrating population or stock entering the areat of operation of the fishery. This concept is used. in part, because of the lack of data on juveniles being recruited to the adult population and migrating from the nursery areas in the Gulf of Guinea. Also, we lack fishing effort data for all of the series. Within the Canary Islands area, however, fishing effort may be assumed relatively stable during the time span of the Mogan and Canarian series. Also, the largest skipjack individuals enter the area of the fishery twice a year as they return from the Azores to the Gulf of Guinea passing through the Canary Islands area a second time. Furthermore, it may be argued that both the classical models and second-order polynomial regressions could be more appropriate to fit the data, meeting mainstream modeling criteria. However, such classical approaches are inappropriate to describe the linked dynamics of multiple steady-state systems (density-dependent and density-independent compensation and depensation, orbits of stability, multiple carrying capacities, and autosimilarity at several scales). We need both conceptual frameworks and statistical techniques that will allow us to understand the dynamics behind the data and link changes in skipjack stocks to fluctuations in the environment. In our view, the system consists of multiple steady states, distinct regimes, qualitatively similar, which should be dynamically linked both to each other and to the environment. A minimum of three constants are needed to describe each equilibrium state and allow the linkage between the steady states. Furthermore, while the classical models and second-order fittings may assume that residuals are 
either random or solely caused by noise, we have assumed that residuals may be a combination of both signal and noise. Although dynamic structures may be an artifact of smoothing techniques (i.e., we may obtain cyclic-like patterns after several steps of smoothing upon random data), the temporal evolution and the structures observed in the phase spaces upon the standardized data showed that a multi-steadystate system may be more appropriate to understand the mechanics behind the system. Also, the theoretical criteria we put forward may be useful to explain the processes governing both recruitment and stock dynamics in skipjack tuna in the Atlantic and to develop new approaches for the preventive management of the migratory stock.

\subsubsection{The Proposed Equations}

On the one hand, a multiplicative approach formed from a concatenation of functions could exhibit multiple (stable) equilibria and complex dynamics: stock and recruitment may be described by the result of a multiplicative process where the initial number of recruits could be modified by nonlinear functions specific to each substock at a certain spatial location. Such an approach could be an extension of the model proposed by Paulik (1973) for an overall spawner-rceruit system. Ilowever, the drawback of the multiplicative approach is the interdependence between the functions which would imply the collapse of the system once any "near-zero" recruitment occurs or whenever "outliers" or extreme fluctuations appear to control any one of the steady states, any one year. On the other hand, an additive approach such as an extension to the model proposed by Solari et al. (1997), where the stock-recruitment system is described as a summation of nonlinear functions, is extremely flexible and may show complex dynamics for each of the steady states. Nlthough equilibria are linked, they are mathematically independent and the model may describe a wide range of dynamic situations (chaos, cycles, quasi-cycles, standstills). Both of these approaches may be approximated by sixth-order polynomial regressions for a two-steady-state system. Nevertheless, the determination of the generic model functions are beyond the scope of this chapter and several alternatives may be viable either as extensions of aforementioned models or new ad hoc functions that may describe the data within a dynamic framework.

\subsubsection{The Phase Spaces}

These relationships may be assumed to describe the dynamics of the exploited skipjack population irrespective of the fishing effort, assuming the following criteria: fishing mortality may either (1) become asymptotic as the fishery approaches the so-called zero net value (i.e., economic overfishing resulting in benefits reduced to zero followed by a stabilizing reduction in the fishing effort, as suggested by Clark, 1976) or (2) cycle due to a backward bending (depensatory) yield against effort relationship because of either biological overfishing (as described by Pitcher and Parrish, 1993) or reductions in recruitment as a result of either environmental perturbations or the combined effect between the environment and fishing mortality during depensatory trends (as described by Solari et at.. 1997). Both of these assumptions imply that fishing mortality may reach a ceiling that may either be asymplotic during periods of relative environmental stability or follow depensatory trends tou ard lower equilibrium states as the external environment becomes less benign.

\subsubsection{Variable Carrying Capacity (Ceilings, $K_{i}$ )}

This is a central concept in our criteria. While carrying capacity is considered as a single value in the classical approaches, we assume (1) it may be multiple and a threshold between equilibrium states; (2) it will link different equilibria and each particular steady state will show a particular ceiling or value of carrying capacity, and (3) it may be quantitatively different at different spatial scales while remaining similar, qualitatively. In our view, it may be more realistic to consider a population parameter, such as $K_{i}$. as variable. On the one hand, the skipjack population migrates through relatively large geographic ranges where it will encounter a continuous transition scheme with a multiplicity of external perturbations: on the other hand. density-independent inputs will determine different levels of numbers recruited implying a particular $K_{i}$ for each orbit of stability. 


\subsubsection{Minimum Populations (Floors, $P_{i}$ )}

As numbers decrease, due to either fishing mortality or external perturbations, or to the combined effects from both of these factors, each steady state may, gradually, shift toward a critical value or unstable equilibrium under which stock and recruitment will "jump" onto a lower, relatively stable equilibrium state. Also, the per capita reproductive success may decline at lower population levels implying that reduced numbers of individuals are recruited to the area of the fishery. Floors may be approached through either density-dependent or density-independent depensation; both of these depensations combined may generate rapid shifts toward lower equilibria. Furthermore, the proposed system may contain an overall minimum viable population under which (1) no oscillations in stock and recruitment will be detected and (2) the commercial fishery may cease.

\subsubsection{Multiple (Stable) Equilibria}

There is no evidence in the field data to assume the dynamics of the skipjack system are governed by a single attractor and a global carrying capacity and that residuals could solely be a consequence of either random processes or noise. The observed structures and temporal evolution in the data may rather suggest that the skipjack system is governed by at least two (or multiple) attractors (and repellors), which are dynamically linked by multiple carrying capacities and minimum populations through which stock and recruitment may, persistently, evolve and return between a wide range of equilibrium states allowing for stable, periodic, and chaotic dynamics. The trajectories of these steady states may turn in orbits of stability determined both by density-dependent compensatory and depensatory phases. The equilibrium states may be linked through floors (or minimum threshold values) and ceilings (or maximum threshold values) that appear during transitions determined by the combined effect from fishing mortality and environmental fluctuations; these critical values may be regarded as the minimum population for the higher equilibrium state and the carrying capacity for the lower equilibrium. As recruitment reaches $K_{i}$, the system will "jump" onto the higher equilibrium, whereas it will enter the lower equilibrium as $P_{i}$ is approached. Also, we may observe that equilibrium states (1) converge as they tend either to zero or to an overall minimum viable population $\left(K_{0}\right)$ and (2) diverge as they tend to the overall ceiling of the system or maximum carrying capacity $\left(K_{\max }\right)$. Multiple, linked equilibrium states both within and between relevant spatial scales may describe the dynamics of migratory skipjack substocks. Also, classical approaches may describe different unlinked regimes but will not explain the dynamics behind the data. The idea of a dynamic continuum is appealing to describe the phase-space and temporal evolution of a persistent system. Rothschild (1986) suggested that populations reduced by fishing or anthropogenic substances that compensate for reductions in vital rates may easily transit among stable, periodic, and chaotic population dynamics. Garcia (1998) and Sharp et al. (1983) suggested that the Hokkaido sardine series atere characterized by loops and proposed an oscillating system consisting of two strange attractors, linked by some transitional shifts, operating at two different levels of spawners and recruits. Furthermore, Berg and (jete (1988) suggested that stock and recruitment, in a sardine-like population, moved along a path or attractor in some higher-dimension coordinate system; Conan (1994) observed that lobster and snow crab landings in Atlantic Canada may follow two orbits of stability or cycles: Powers (1989) suggested chaotic behavior for a two-species system of fish, and Tyutyunov et al. (1993) demonstrated cycles of different periods and chaos in population dynamics of perch from ten lakes. Moreover. Caddy (1998) pointed out several other cases, in semienclosed areas, where stock and recruitment dynamics could be linked to oscillatory phenomena: (1) an apparent 9- to 18-year periodicity for the Bay of Fundy scallop stocks (Caddy, 1979); (2) a 12-year fishing-effort-independent periodicity in the landings of both hatke and red multer at the island of Mallorea in the Mediterranean Sea (Astudillo and Caddy, 1986): and (3) a 12-to 13-year oxcillatory pattern in the catches of the Adriatic sardine.

\subsubsection{Compensatory and Depensatory Dynamics}

In each steady state, oscillations may be due to both density-dependent compensation (numbers increase) and depensation (numbers decrease); stock and recruitment will be affected by shor- and medium-term 
external perturbations, oceanographic diffusion-advection processes, migration between schools, availability of food items, fishing mortality, and catch-effort oscillations, as well as several other both internal (population) and external (environmental, fishing related) factors that will determine the temporal evolution of an equilibrium state. Also, transitions between equilibria may be caused either by densityindependent compensation (as the environment becomes more benign and recruitment increases) or density-independent depensation (as external stress increases). While fishing mortality may be incremented during density-independent compensation, reductions may not be enough while density-independent depensation is operating. Also, the combined effects of fishing mortality during both densitydependent and -independent depensation may imply the rapid shift toward both the floor of an equilibrium and, hence, a lower steady state.

\subsection{7 [xtinction of the Commercial Fishery}

Fonteneau (1987) observed that recruitment overfishing has never been suggested for skipjack in the Atlantic. The steady states observed in the skipjack system appear to be persistent within relatively wide ranges of stability. Also, the stability of equilibrium states may be further enhanced by catch and effort oscillations as economical overfishing is being approached. However, several mechanisms could generate both recruitment overfishing and the (temporal) extinction of the fishery. On the one hand, environmental medium-term disturbances in the nursery grounds may cause the skipjack system to shift toward low equilibria with decreasing amplitude between maxima and minima; on the other hand, both types of depensation combined with a relatively constant fishing mortality may imply that the skipjack system evolves toward an overall minimum viable population with no oscillations.

\subsubsection{Migration through a Fractal Marine System}

While the studied time series showed quantitatively different qualities such as dynamic similarity observed in the two-equilibrium system, memory and periodicity may be similar features to all of the cases. These results may open up an interesting field of work in the research on exploited skipjack populations in the Atlantic. The correspondence between the series and similarity in the phase spaces may suggest that stock and recruitment relationships may be caused by deterministic mechanisms with similar dynamics at several spatial scales. This may imply that we could (1) estimate complex processes governing recruitment and migration in skipjack; (2) link population processes between different spatial scales relevant to the dynamics of the migratory stock; (3) forecast recruitment in wider areas frum local series at certain spatial locations, and (4) estimate future recruitment in minor spatial locations from overall CECAF series taking into consideration the detected time lags. To discuss these ideas further, we simulated a self-similar system through the iteration of the funcrion $f(x)=x^{2}+m$. We allowed the function the random choice between two possible inverses $(+1$ or -1$)$ and let the iteration run until we obtained an arbitrary number of data points $(N=19851)$. The data were standardized and the system is shown in Figure 12.10. All variables $(R, \mathrm{IM})$, the initial value of the parameter $(m)$, and the number of iterations were arbitrary. To construct a dynamically referenced description of the data, we fitted the output to a linear regression, a sixth-degree polynomial, a cubic spline (to show more detailed local dynamics), and 50 and $95 \%$ bivariate ellipses (also, confidence intervals), as well. Furthermore, we sampled the simulated series both randomly and sequentially to $10,5,1$, and $0.1 \%$ of the total number of points (to resemble different spatial scales or sampling windows) and, in all cases, we obtained similar tendencics: as in the skipjack fishery, the simulated system showed results with similar dynamic patterns at different sampling windows. Although the tendencies remain similar at several scales, we may obtain different levels of numbers depending on the quadrant in which we carry out the sampling. As the skipjack stock migrates through the ocean, it will be affected by a multiplicity of external perturbations of dynamic nature. There is an increasing body of evidence suggesting that the upper ocean layer through which the skipjack is recruited and migrates may be both of fractal nature and affected by multifractal processes: the spatial distribution of foam and white caps (Kerman and Szeto, 1994), wind-wave breaking (Raizer et al., 1994) and breaking of waves (Kerman and Bernier, 1994). distribution of sea surface temperature ( $\mathrm{Fu}, 1994,1995)$, isotherm lengths and patterns of the sea surface temperature in mesoscale 


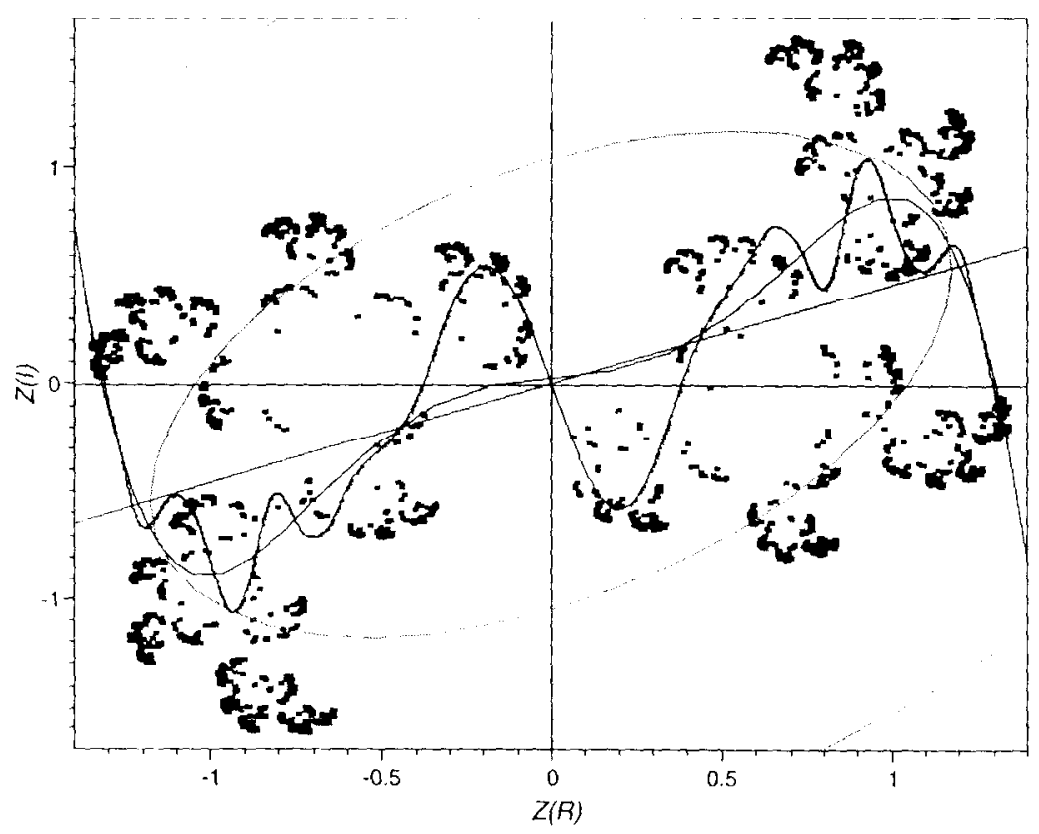

FIGURE 12.10 A theoretical self-similar system resembling a stock-in-area $[Z(R)]$ recruitment-to-the-area $[Z(I)]$ relationship. Data values $(N=19851)$ are dynamically referenced through linear regression, a sixth-degree polynomial, a cubic spline (to show more detailed local dynamics) and $50 \%$ (inner) and $95 \%$ (outer) bivariate ellipses (also, confidence intervals). The random and sequential sampling of $10,5,1$, and $0.1 \%$ of the total number of points (resembling captures from different spatial scales) showed similar tendencies: as in the skipjack fishery, the simulated system shows similar dynamic patterns at different sampling windows. Different levels of numbers are obtained depending on the quadrant sampled. Iteration and data, parameter values, and functions are arbitrary.

turbulence (Bunimovich et al., 1993), and fractal behavior of the temperature isolines and properties of frontal regions (Marullo et al., 1993) may be examples of factors that determine recruitment patterns and spatial distributions in fishery areas. Also, such fractal structures in the ocean may explain the dynamic similarities we have proposed for the skipjack system at the three spatial scales. If a skipjack stock diffuses-advects through a fractal ocean with similar properties at several scales, we might expect the equilibrium states we observe in the skipjack system to show a certain degree of autosimilarity, as well. Assuming the theoretical criteria proposed in our framework, we could develop a method based on remotely sensed data with which we could estimate the dynamics of one or several substocks of skipjack from a few spatial windows. Block et al. (2001) reported electronic, satellite-1racked tag recovery data on both vertical-diagonal and transatlantic (Gulf of Mexico-Mediterranean Sea) migration of bluefin tuna. The incorporation of data that show depth boundaries in una migration combined with sea surface comperature. recruitment-to-the-area and catches may allow for the determination of the dynamic three-dimensional system (hatude. longitude, depth) through which tuna migrates: a multisteady-state framework as proposed in this chapter may incorporate all of the variables to describe this hyperspace. Such an approach could be critucal both for the eonservation of tuna and the preventive control of the fishery. Also, it may become the ground for the development of a formal theory for both system behavior and migrations in skipjack and other tunas. Classical approaches assume a single spatial scale, an equilibrium state, and a sole value of carrying capacity. It is critical to realize that a dynamic framework will enable us to understand both the temporal evolution of the skipjack system and the causal mechanisms behind the data.

\section{Acknowledgments}

John Caddy and Serge Garcia (FAO/Fishery Resources Division. Rome, Italy) and Sami Souisis and Laurent Seuront (Ecosystem Complexity Research Group. Université des Sciences el Technologies de litle, Lrance) are acknowledged for their encouragement and comments. This study was funded, in 
part, by the Ministry of Fisheries and Agriculture of the Canarian Government (Consejería de Agricultura y Pesca del Gobierno Autónomo de Canarias) through the Grant 540/1998 to the Las Palmas University Foundation (Fundación Universitaria de Las Palmas).

\section{References}

Ariz, J., R. Delgado de Molina, J.C. Santana, and A. Delgado de Molina. 1995. Datos estadísticos de la pesquería de túnidos de las islas Canarias durante el período 1975-93. Colección de documentos científicos, ICCAT, 44(2).

Astudillo, A. and J. Caddy. 1986. Periodicidad de los desembarcos de merluza (Merluccius merluccius) y salmonete (Mullus sp.) en la isla de Mallorca, in Int. Symp. Long Term Changes Mar. Fish Pop., V.T. Wyatt and M.G. Larrañeta, Eds., Vigo, Spain.

Atkinson, C.A. 1987. A nonlinear programming approach to the analyses of perturbed marine ecosystems under model parameter uncertainty. Ecol. Modelling 35:1-28.

Bas, C., A.P. Solari, and J.M. Martín. 1999. Considerations over a new recruitment model for exploited fish populations. R. Acad. Sci. Barcelona 58(5):157-183.

Bayliff, W.H. 1988. Integrity of schools of skipjack tuna, Katsuwonus pelamis, in the eastern Pacific Ocean, as determined from tagging data. Fish. Bull. 86:631-643.

Berg, M. and W. Getz. 1988. Stability of discrete age-structured and aggregated delay-difference population models. J. Math. Biol. 26:551-581.

Beverton, R.J. and S.J. Holt. 1957. On the dynamics of exploited fish populations. Ministry of Agriculture, Fisheries and Food, London. Fisheries Investigation Series 2(19).

Block, B.A., H. Dewar, S.B. Blackwell, T.D. Williams, E.D. Prince, C.J. Farwell, A. Boustany, S.L. Teo, A. Seitz. A. Wall. and D. Fudge. 2001. Migratory movements. depth preferences, and thermal biolngy of Atlantic bluefin tuna. Science 293:1267.

Bochlert, G.W. and B.C. Mundy. 1994. Vertical and onshore-offshore distributional patterns of tuna larvae in relation to physical habitat features. Mar. Ecol. Prog. Ser. 107:1-13.

Bunimovich, L.A., A.G. Ostrovskii, and S. Umatani. 1993. Observations of the fractal properties of the Japan sea surface temperature patterns. Int. J. Remote Sens. 11:2185-2201.

Caddy, J. 1979. Long-term trends and evidence for production cycles in the Bay of Fundy scallop fishery. Rapp. P.-V. Réun. Cons. Int. Explor. Mer. 175:97-108.

Caady, J. 1998. Personal communication. Letter from the Chief, Marine Resource Service, Fishery Resources Division, Food and Agriculture Organization (FAO), Rome, Italy.

Castro, J.J., A.P. Solari, J.M. Martin Gonzalez, and C. Bas. 1999. Recruitment to the fishery of the skipjack tuna Katsuwonus pelamis in Canary Islands: application of a new conceptual model. Fisheries Resource Group, University of Las Palmas. Report for the project funded by the Ministry of Fisheries of the Canarian Government (Consejería de Pesca del Gobicrno Automono de Canarias) through the Las Palmas University Foundation (Grant 540. December. 1998). In Spanish.

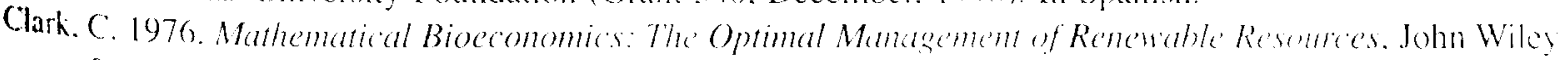
\& Sons, New York.

Conan, G. 1994. Can simple linear correlation satisfactorily detect environmental or interspecific effects on fisheries landings in a chaotic oceanic universe? ICES-Council Meeting. P/8.

Conrad, M. 1986. What is the use of chass? in Chaos: Nonlinear Science. Theory and Applications. A.V. Holden. Ed.. Manchester University Press, U.K., 1-14

Cushing. D.H. 1977. The problems of stock and recruitment, in Fish Population Dynamics, J.A. Gulland, Ed., John Wiley \& Sons. New York, 116-1.33.

De Angels, D.L. 1988. Strategies and difficulties of applying models to aquatic populations fond webs. Ecol. Modelling 43:57-73.

E40. 2001. Map of the CECAF Division 34. Food and Agriculture Organization. Fisheries Circular 835 Rev. 1 . Summary Intormation on the Role of International Fishery Bodies with Regard to the Conservation and Management of Living Resources of the High Seas, prepared by M.J. Savini in 1991. FAO-Fisheries

Home Page at hitp://www. fao.org/ti/body/body.asp.
Reder, P.C. and II.J. Bernard. 1987. Tuna aggregation and reeding near fronts observed in satellite imagery. Cont. Shelf Re's. 7:871-881. 
FISHSTAT/FAO. 1999. FISH STAT Plus version 2.0. FAO Fisheries Department. Fishery Information, Data and Statistics Unit (FIDI). Database of Nominal catches and landings reported to regional commissions. http://www.fao.org/WAICENT/FAOINFO/FISHERY/struct/fidif.htm.

Fogarty, M. 1993. Recruitment in randomly varying environments. ICES J. Mor. Sci. 50:247-260.

Fonteneau, A. 1987. Competition between tuna fisheries - critical review based on Atlantic examples Collective Volume of Working Documents, Expert Consultation on Stock Assessment of Tunas in the Indian Ocean, Colombo, Sri Lanka, 4-8 December, 1986. FAO/UNDP Indo-Pacific Tuna Development and Management Programme, 195-213.

Fonteneau, A. 1991. Modelización, gestión y ordenación de las pesquerías atuneras del Atlántico centro-este. Modelling and management of the tuna fisheries in the central-eastern Atlantic. International Conmituee for the Conservation of Atlantic Tunas, ICCAT, 37:344-387.

Fonteneau, A. 1997. A critical review of tuna stocks and fisheries trends world-wide, and why most tuna stocks are not yet overexploited, in Developing and Sustaining World Fisheries Resources. The Stute of Science and Management, D.A. Hancock, D.C. Smith, A. Grant, and J.P. Beumer. Eds. Commonwealth Scientific and Industrial Research Organ (CSIRO), Collingwood, Australia, 39-48.

Fonteneau, A. and I. Marcille. 1993. Resources, fishing and biology of the tropical tunas of the eastern Central Atlantic. Fish. Tech. Pap., (FAO), 292, 354 pp.

Fu, Y. 1994. Relationship between sea surface temperature and typhoon analysed by fractal dimension. Trans. Oceanol. Limnol. 3:10-17.

Fu, Y, 1995. Fractal analysis and forecast of monthly average sea surface temperature. Mar. Forecasts 1:49-54.

Garcia, S. 1998. Personal communication. Letter from the Director of the Fishery Resources Division, Fisheries Department, Food and Agriculture Organization (FAO), Rome, Italy.

Gulland, G. A. 1989. Fish populations and their management. J. Fish Biol. 35(Suppl. A:1-9). C.E. Hollingworth and A.R. Margetts, Eds., Fisheries Society of the British Isles, Sawson, Cambridge, U.K.

Hernández-García, V., J.L. Hernández-López, and J.J. Castro. 1998. The octopus (Octopus vulgaris) in the small-scale trap tishery oft the (anary Islands (Central-East Atlantic). Fish. Res. 35:183-189.

Hilborn, R. 1991. Modelling the stability of fish schools: exchange of individual fish between schools of skipjack tuna (Katsuwonus pelamis). Can. J. Fish. Aquat. Sci. 48:1081-1091.

ICCAT. 1980. Proceedings of the International Conmission for the Conservation of Allantic Tunas (ICCAT) Conference on the International Skipjack Year Program. P. Symon, P. Miyake, and G. Sakagawa. Eds., $388 \mathrm{pp}$.

Kerman, B. and L. Bernier. 1994. Multifractal representation of breaking waves on the ocean surface. J. Geophys. Res. Oceans C8:16179-16196.

Kerman, B. and K. Szeto. 1994. Fractal properties of white caps. Atmos. Ocean 32:531-551.

Marullo, S, A Provenzale. R Santoleri, and R. Villone. 1993. Fractal fronts in the Mediterrancan Sea Ann. Geophys. Atmos. Hydrospheres Space Sci. 2(3):111-118.

Oppenheim. A.V. and R.W. Schafer. 1975. Digital Signal Processing. Prentice-Hall. Englewood Cliffs. NJ. 556.

Ovchinnikov. V.V., V.Z. Gaikov. Y.P. Fedoseev, and V.G. Shcheglov. 1988. Main results of realization of the Soviet program of tuna tagrging in the Athantic () eats. Collective Volume of Working Documents.

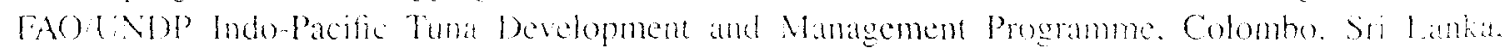
224.226.

Pagavinu, M. and D. Gaerner. 1994. Variación espacio-temporal de las capturas de atunes aleta amarillat y listado realizadas por la flota venezolana de superficie en el Mar Caribe, entre 1988 y 1902 ISpatiotemporal variations of the yellowfin and skipjack catches by the Venezuclan surface lleet in the Caribbean Sea trom 1988 to 19921. Mechng of the $10 \mathrm{CAl}$ Working Group to Evaluate Atlantic Yellowtm luna. Tenerife. Canary Islands. Spain, 3-9 June 1993. ICCAT 42(2):314-318.

Paulik. G.J. 1973. Studies of the possible form of the stock-recruitment curve. Repp. P.-V. Re'um. Coms. Imt. E.yplor. Me'. 164:302-315.

Pitcher, T. and J. Parrish. 1993. In Behoviour of Teleest Fishes. Fish and Fisheries Series 7. Chapman \& Hall. New York, 372-374.

Piton. B. and C. Roy. 1983. Annec internationale listas: Donnes d environnement pour la periede juin, juillet et aout 1981 dans le golfe de Guinee flnternational "listalo" (skipjack) year: convironmental data for the peried June. July and August 1981 in the Gulf of Cinineal. Collert. Wol. Sir. Pap. 1861):205:253.

Powers. J.E. 1989. Multispecies modelo and chantic dynamics. ICES-MSM. P/21. 
Raizer, V.Y., V.M. Novikov, and T.Y. Bocharova. 1994. The geometrical and fractal properties of visible radiances associated with breaking waves in the ocean. Ann. Geophys. Atmos. Hydrospheres Space Sci. 12:1229-1233.

Ramos, A. and P. Sangrá. 1992. Características oceanograficas en el area de Canarias: Relación con la pesquería de listado (Katsuwonus pelamis) lOceanographic characteristics of the area of the Canary Islands: relationship with the skipjack fishery (Katsuwonus pelamis)]. Meeting of the ICCAT Standing Committee on Research and Statistics, Madrid, Nov. 1991. ICCAT 39(1):289-296.

Ramos, A., I. Kamirez, and J. Yajuelo. 1991. Aspectos biologicos del Katsuwonus pelamis en aguas del Archipiélago Canario: Reproducción [Biological aspects of Katsuwonus pelamis in waters of the Canary Islands: Reproduction]. Meeting of the ICCAT Standing Committee on Research and Statistics, Madrid, Nov. 1990. ICCAT 35(1):14-21.

Ramos, A., P. Sangrá, A. Hernandez-Guerra, and M. Cantón. 1991. Large and small scale relationship between skipjack tuna (Katsuwonus pelamis) and oceanographic features observed from satellite imagery in the Canary Islands area. Meeting of the International Council for the Exploration of the Sea, La Rochelle, France, 26 Sept.-4 Oct. 1991. ICES C. M. Pap. L:78.

Ricker, W.E. 1954. Stock and recruitment. J. Fish. Res. Board Can. 11:559-623.

Ricker, W.E. 1975. Conputation and interpretation of biological statistics of fish populations, Bull. Fish. Res. Board Can. 191:382 pp.

Roger, C. 1994a. Relationships among yellowfin and skipjack tuna, their prey-fish and plankton in the tropical western Indian Occan. Fish. Oceanogr. 3(2):133-141.

Roger, C. 1994b. On feeding conditions for surface tunas (yellowfin, Thunnus albacares and skipjack, Katsuwonus pelamis) in the western Indian Ocean. Proceedings of the 5 th Expert Consultation on Indian Ocean Tunas, Scychelles, 4-8 Oct. 1993. FAO/UNDP Indo-Pacific Tuna Development and Management Programme, IPTP 1994, 8:131-135.

Roger, C. and E. Marchal. 1994. Mise en evidence de conditions favorisant l'abondance des albacores, Thunnus albacares, et des listaos, Katsuwonus pelamis, dans l'Atlantique equatorial est [Conditions favoring the abundance of yellowfin (Thunnus albacares) and skipjack (Katsuwonus pelamis) in the eastern equatorial Atlantic]. Meeting of the ICCAT Working Group to Evaluate Atlantic Yellowfin Tuna, Tenerife, Canary Islands, Spain, 3-9 June 1993. ICCAT 42(2):237-248.

Rothschild, B.J. 1986. Dynamics of Marine Fish Populations, Harvard University Press, Cambridge, MA.

Sharp, G., J. Csirke, and S. Garcia. 1983. Modelling fisheries: what was the question? FAO Fish. Rep. 291(3):1177-12.24

Shepherd, J.G. 1982. A versatile new stock-recruitment relationship for fisheries, and the construction of sustainable yield curves. J. Cons. Int. Explor. Mer 40:67-75.

Solari. A.P., J.M. Martín-González, and C. Bas. 1997. Stock and recruitment in Baltic cod (Gadus morhua): a new, non-linear approach. ICES J. Mar. Sci. 54:427-443.

Tyutyunov, Y., R. Arditi, B. Buettiker, Y. Dombrovsky, and E. Staub. 1993. Modelling fluctuations and optimal harvesting in perch populations. Ecol. Modelling 69:19-42.

Wise, J. 1985. Probable underestimates and misreporting of Atlantic small tuna catches, with suggestions for improvement. Meeting of the ICCAT Standing Committee on Research and Statistics, Palma de Mallorca, Spain, Nov. 1985. Collect. Vol. Sci. Pap., 25:324-332. 